\title{
Spatial variation in coda $Q$ around the Nobi fault zone, central Japan: relation to S-wave velocity and seismicity
}

Sugane Tsuji ${ }^{1}$, Yoshihiro Hiramatsu ${ }^{2^{*}}$ and The Japanese University Group of the Joint Seismic Observations at the Area of Nobi Earthquake ${ }^{3}$

\begin{abstract}
We investigate the spatial variation in coda $Q$ around the Nobi fault zone in a high strain rate zone to assess the relation between coda $Q$, shear wave velocity, and seismicity. Waveform data were obtained from dense seismic observations. Low coda $Q$ that follows the Niigata-Kobe Tectonic Zone in the high strain rate zone is distinct at the lowest frequency band of 1 to $2 \mathrm{~Hz}$. However, at higher frequencies, such a spatial pattern in coda $Q$ is unclear. A good positive correlation was found between coda $Q$ at the 1 - to $2-\mathrm{Hz}$ frequency band and the S-wave velocity perturbation at $25-\mathrm{km}$ depth, which suggests that the coda $Q$ reflects the ductile deformation below the brittle-ductile transition zone. Furthermore, coda $\mathrm{Q}$ at the 1- to $2-\mathrm{Hz}$ frequency band correlates negatively with seismicity at 10- to 15-km depth, which implies that there is a high stressing rate in the low coda $Q$ area. These facts, together with results of previous studies, imply that a high deformation rate below the brittle-ductile transition zone produces the high strain rate observed by the Global Positioning System (GPS) on the surface in this region.
\end{abstract}

Keywords: Heterogeneity; Low velocity; Strain rate; Brittle-ductile transition zone; Ductile deformation; Attenuation; Seismicity

\section{Findings}

Introduction

Recent advances in high-quality seismic wave and geodetic data analyses have revealed how a rupture propagates along the fault planes of a large earthquake. Nevertheless, the earthquake nucleation process has not been resolved. Especially, stress accumulation at deeper parts of a fault, which is a key to nucleation, is important to elucidate the generation process of a large inland earthquake. A zone of high strain rate concentration has been identified in central Japan from analyses of dense Global Positioning System (GPS) network data: the NiigataKobe Tectonic Zone (Sagiya et al. 2000) (Figure 1). The strain rate in the zone is 1 order of magnitude higher than that in surrounding areas.

This zone is also characterized historically by large inland earthquakes. The Nobi earthquake in 1891, which

\footnotetext{
* Correspondence: yoshizo@ staff.kanazawa-u.ac.jp

${ }^{2}$ Faculty of Natural System, Institute of Science and Engineering, Kanazawa

University, Kakuma, Kanazawa 920-1192, Japan

Full list of author information is available at the end of the article
}

is regarded as the largest class of inland earthquakes in Japan, occurred in this zone. The source fault of the Nobi earthquake consists of several faults called the Nobi fault zone (Figure 1). Seismic tomographic studies show that a low-velocity anomaly is distributed in the lower crust beneath this zone (Nakajima and Hasegawa 2007; Matsubara et al. 2008). The strength of the stressinduced shear wave polarization anisotropy is proportional to the strain rate in and around the high strain rate zone in Japan (Hiramatsu et al. 2010).

Another interesting feature is the decay rate of coda waves that comprise $\mathrm{S}$ to $\mathrm{S}$ back-scattering waves generated by heterogeneities in the lithosphere, termed coda $Q$. The inverse of coda $Q, Q_{C}^{-1}$, represents the strength of attenuation. Coda $Q$ includes both intrinsic absorption and scattering attenuation. Many researchers have reported a temporal variation in coda $Q$ (e.g., Jin and Aki 1989; Hiramatsu et al. 2000). Such variation is possibly induced by a change in scattering properties of the medium attributable to crack opening, closing, healing, pore pressure change, fluid movement, aseismic creep activity, and 

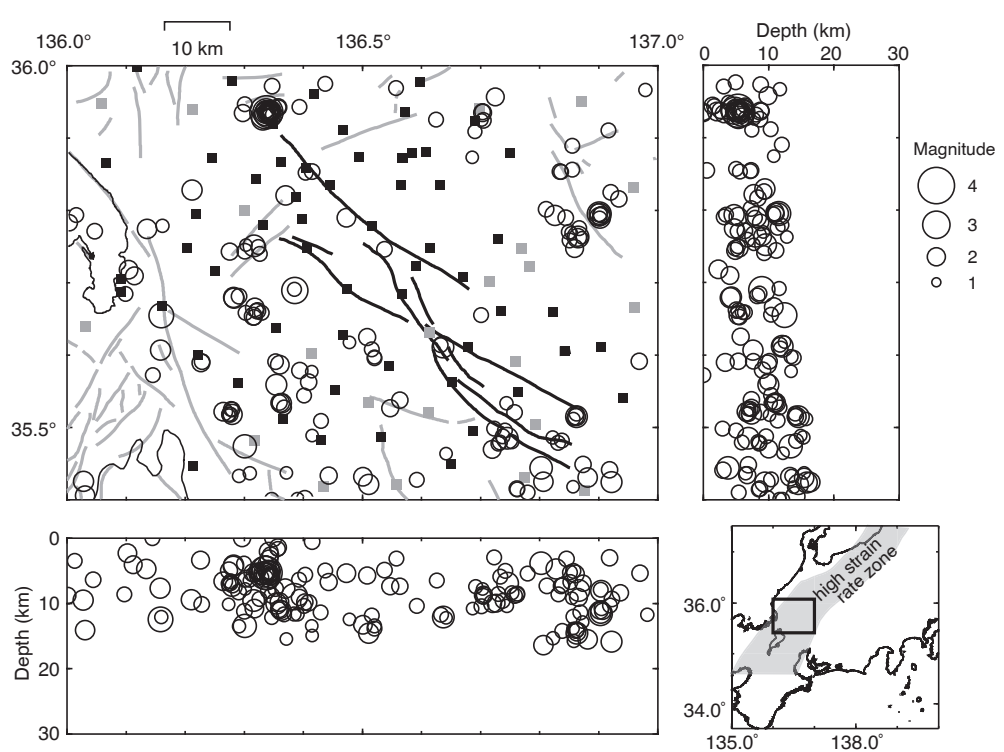

Figure 1 Distributions of earthquakes (circles) and stations (squares) used for this study. Black and gray squares represent temporal and permanent stations, respectively. Gray lines show Quaternary active faults. Black lines show active faults of the Nobi fault zone. A gray zone in the lower right panel shows the high strain rate zone termed the Niigata-Kobe Tectonic Zone.

so forth. Jin and Aki (2005) investigated the spatial variation in coda $Q$ in Japan and first reported that a low coda $Q$ zone at the 1- to $2-\mathrm{Hz}$ and 2- to $4-\mathrm{Hz}$ frequency bands corresponds to the high strain rate zone. Hiramatsu et al. (2013) investigated details of the spatial variation in coda $Q$ around the Atotsugawa fault zone, central Japan, in and around the high strain rate zone. They found that low coda $Q$ at lower frequency bands is localized along the Atotsugawa fault zone, in other words, along the center of the high strain rate zone. Hiramatsu et al. (2013) compared the perturbation of S-wave velocity at different depths (Nakajima et al. 2010) to the value of coda Q. Their results showed that the spatial distribution of low coda $Q$ at lower frequency bands correlates well with low velocity at $25-\mathrm{km}$ depth, which implies that the spatial variation in coda $Q$ at lower frequency bands is attributed to seismic properties at $25-\mathrm{km}$ depth.

To investigate the heterogeneity of seismic structure from the crust to the mantle and its relation to stress accumulation, the Japanese University Group of the Joint Seismic Observations at the Area of Nobi Earthquake has conducted dense seismic observations around the Nobi fault zone since 2009. Hiramatsu et al. (2013) proposed that coda $Q$ at lower frequencies is an indicator of the deformation rate below the brittle-ductile transition zone in the crust, and their results showed good spatial correlation between coda $Q$ and seismicity. The variation in seismicity around the Nobi fault zone (Figure 1) is expected to be useful to evaluate this proposition.

This study investigates the spatial distribution of coda $Q$ around the Nobi fault zone using a dense seismic network.
Moreover, we examine the relation between the spatial distribution of coda $Q$, shear wave velocity, and seismicity.

\section{Data and methods}

We used seismic waveform data recorded at 82 stations, which include 59 temporal stations. These data were obtained from the Japanese University Group of the Joint Seismic Observations at the Area of Nobi Earthquake, Earthquake Research Institute, The University of Tokyo; the Disaster Prevention Research Institute, Kyoto University; Nagoya University; the Japan Meteorological Agency; and Hi-net operated by the National Research Institute for Earth Science and Disaster Prevention around the Nobi fault zone (Figure 1). We analyzed 187 events during May 2009 to August 2012 that had magnitudes greater than 1.8 and source depths that were shallower than $30 \mathrm{~km}$ in the analyzed region. The hypocenter catalog of the Japan Meteorological Agency was used for the selection of these events.

Each original seismogram is band-pass filtered to five frequency bands: 1 to 2,2 to 4,4 to 8,8 to 16 , and 16 to $32 \mathrm{~Hz}$. We calculated the root-mean-square (RMS) amplitude in a moving time window with a duration of $4 / f$ for each frequency band, where $f$ is the center frequency of each band. We then applied the single back-scattering model (Aki and Chouet 1975) of

$$
\ln A_{C}(f \mid t)=-\ln t-\pi f Q_{C}^{-1} t+\text { const }
$$

where $A_{C}(f \mid t)$ is the RMS amplitude of band-pass-filtered coda waves at the center frequency of $f$ and lapse time 
of $t$, and $Q_{C}{ }^{-1}$ is the inverse of coda $Q$. The value of $Q_{C}{ }^{-1}$ was calculated by fitting Equation 1 for each band and averaging over three components at each station using a logarithmic value of $Q_{C}{ }^{-1}$. However, reflected phases occasionally disturb the monotonous coda decay and cause fluctuation of coda $Q$. Instead of a simple least squares method, robust estimation by the criteria of the least absolute deviation was deemed more appropriate to fit Equation 1 to $A_{C}(f \mid t)$ for the estimation of coda $Q$ (Hiramatsu et al. 2000).

The time window for the estimation of coda $Q$ is twice of the $\mathrm{S}$-wave travel time to the lapse time of $30 \mathrm{~s}$ after the origin time. If the coda tail is shorter than $30 \mathrm{~s}$, then the end of the time window is set to the time at which the amplitude reaches twice the noise level for each frequency band. If the length of the time window is less than $10 \mathrm{~s}$, then we did not analyze it for this study. We also eliminated stations with analyzed event numbers of less than 10. Finally, from 175 events (Figure 1), we used coda $Q$ values obtained at 70 stations for the frequency bands of 1 to 2,4 to 8,8 to 16 , and 16 to $32 \mathrm{~Hz}$ and at 69 stations for the frequency band of 2 to $4 \mathrm{~Hz}$ for the following discussion.

Variations in data such as the source depth and the lapse time might engender apparent variation in coda $Q$. However, we can confirm that those factors do not affect the value of coda $Q$ because no correlation was found between the value of coda $Q$ and the source depth or between the value of coda $Q$ and the lapse time in this study.

Temporal variation in coda $Q$ before and after the 2011 off the Pacific coast of Tohoku earthquake

Before we discuss the spatial relation between coda $Q$, shear wave velocity, and seismicity, it is necessary to examine the temporal variation in coda $Q$ induced by a static stress change caused by the 2011 off the Pacific coast of Tohoku earthquake (hereinafter, the Tohoku earthquake). Padhy et al. (2013) examined temporal changes in $Q_{C}{ }^{-1}$ associated with the Tohoku earthquake using nine stations along the Pacific coast of northeastern Japan. They reported an increase of $Q_{C}^{-1}$ (decrease of coda $Q$ ) by about $10 \%$ to $16 \%$ for the frequency bands of 1.25 to $3.5 \mathrm{~Hz}$ after the Tohoku earthquake at stations inside the source region. They also reported no temporal changes of $Q_{C}{ }^{-1}$ at stations outside the source region. No significant temporal changes in $Q_{C}{ }^{-1}$ were found for higher frequency bands at the stations, which showed a significant increase of $Q_{C}{ }^{-1}$ at the lower frequency bands. These frequency-dependent temporal changes are consistent with temporal changes that occurred in $Q_{C}{ }^{-1}$ in the Tamba region due to the static stress change associated with the 1995 Hyogo-ken Nanbu earthquake in Japan (Hiramatsu et al. 2000).
We used coda $Q$ averaged over stations for an earthquake and regard its standard deviation as the error of each coda $Q$. After dividing the data into two periods of 22 months before and 17 months after the Tohoku earthquake, we evaluated the change in the average value of coda $Q$ between the two periods. The average values of coda $Q$ for all frequency bands increase slightly, up to $4 \%$ (shown as a decrease of the average of $\log _{10} Q_{C}{ }^{-1}$ in Figure 2), after the Tohoku earthquake. Their variations are less than 1 standard deviation of the average. We applied $t$ tests to examine these temporal variations and determined that no variations were statistically significant. This result was also found for the subareas, which include the eastern and western areas of the analyzed region. The temporal variation in coda $Q$ for each frequency band of each station, which includes more than 10 events in each period, was also examined. The temporal variation in coda $Q$ varies from station to station. Some stations show an increase of coda $Q$, whereas others show a decrease, and still others show no change. Applying $t$ tests to the variation showed that no variation was statistically significant. Therefore, we used the averaged values of coda $Q$ over earthquakes for the analyzed period at each station to determine the spatial variation in coda $Q$ in the analyzed region.

The effective static stress change that modulates the heterogeneity of the cracked media can be represented by the Coulomb failure stress $(\triangle \mathrm{CFS}$ ) (Hiramatsu et al. 2000, 2005). For example, an increase of $Q_{C}{ }^{-1}$, which represents a strengthening of attenuation, at the lower frequency bands was observed in the positive $\triangle \mathrm{CFS}$ region associated with the 1995 Hyogo-ken Nanbu earthquake in southwestern Japan (Hiramatsu et al. 2000). Moreover, an increase in the strength of shear wave splitting was also reported in the positive $\triangle \mathrm{CFS}$ region caused by a moderate-sized earthquake in central Japan (Hiramatsu et al. 2005).

There is a wide variety of strike, dip, and slip for active faults in the analyzed region (Research Group for Active Faults in Japan 1991; Headquarters for Earthquake Research Promotion 2014) (Figure 1). These faults might control the crack distribution around the faults, signifying a heterogeneous distribution of cracks. Consequently, the spatial variation of $\triangle \mathrm{CFS}$ that affects the cracks is heterogeneous. For example, the rectangular fault model of the Tohoku earthquake (Geospatial Information Authority of Japan 2011) provides a $\triangle$ CFS of -13 to $+23 \mathrm{kPa}$ for major active faults in the analyzed region. For calculations, we used the expression of Okada (1992) with an effective friction coefficient of 0.4 , a Poisson ratio of 0.25 , and a rigidity of $30 \mathrm{GPa}$. Such a heterogeneous distribution might enhance heterogeneity in some areas and reduce it in other areas. For that reason, no significant temporal variation in coda $Q$ associated with the Tohoku earthquake could be recognized in the analyzed region. 


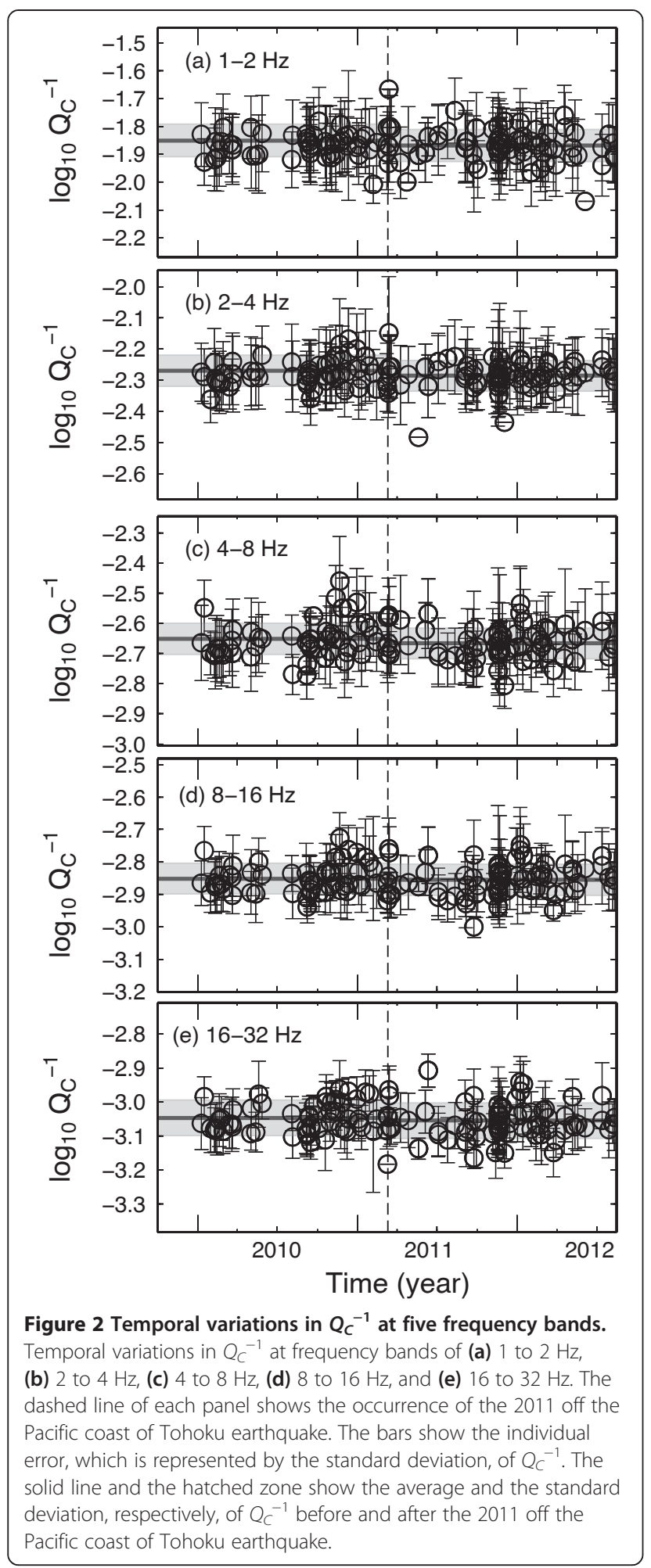

Spatial correlation between coda $Q$ and the shear wave velocity

We constructed a map of coda $Q$ around the Nobi fault zone using the values of coda $Q$ averaged over earthquakes at each station. Coda waves sample a volume, which is represented by an ellipsoid with focuses of a hypocenter and a station. The single back-scattering model shows that the lapse time of $30 \mathrm{~s}$ corresponds to the farthest scatterers being located within $45 \mathrm{~km}$ from the station (Jin and Aki 2005). A dense distribution of both the hypocenters and the stations makes the sampling volumes of coda waves overlap each other. We, thus, distributed the values of coda $Q$ averaged over earthquakes at each station simply to the location of each station. Then, the values of coda $Q$ at each station were averaged over $10 \mathrm{~min}$ (longitude) $\times 5$ min (latitude) squares with a 1-min interval and were smoothed using the surface command of Generic Mapping Tools (GMT) software (Wessel and Smith 1998) in the analyzed region (Figure 3). This procedure, which is similar to that described by Jin and Aki (2005), is regarded as approximate for a homogeneous velocity structure. In Figure 3, we use the same color scale as that described by Jin and Aki (2005) for the spatial distribution of coda $Q$ in the Japanese islands.

The obtained values of coda $Q$ in this study are almost coincident with those of Jin and Aki (2005) for all frequency bands. The spatial distribution of coda $Q$ was difficult, however, to relate to the distribution of active faults. No distinct distribution was found along the Nobi fault zone. At the 1 - to $2-\mathrm{Hz}$ frequency band, almost the entire region is characterized by coda $Q$ values below 100 , and this is consistent with previous works in the high strain rate zone (Jin and Aki 2005; Hiramatsu et al. 2013). The variation in coda $Q$ reaches approximately $30 \%$ at the 1 - to $2-\mathrm{Hz}$ frequency band (Figure $3 \mathrm{a}$ ). The area from northeast to southwest is characterized by low coda $Q$ values below 75 at this frequency band. This low coda $Q$ area shows the same trend as that of the distribution of the high strain rate zone in this region, although the variation in the strain rate is not as large in this region. The consistencies in the trends between the low coda $Q$ values and the high strain rate zone are the same as those in the region around the Atotsugawa fault zone (Hiramatsu et al. 2013). However, for higher frequencies, it was difficult to find such a consistent pattern of coda $Q$ with the high strain rate zone trending from northeast to southwest (Figure 1). Jin and Aki (2005) reported that coda $Q$ at the 2- to $4-\mathrm{Hz}$ frequency band showed low values along the high strain rate zone at the Japanese islands scale. However, their map of coda $Q$ at the 2- to $4-\mathrm{Hz}$ frequency band in the analyzed region is not characterized by low values, which is consistent with results of the present study.

It is particularly interesting to find that the distribution of coda $Q$, especially at the 1 - to $2-\mathrm{Hz}$ frequency band, reflects the depth of the seismic property. We focus here on the distribution of shear wave velocity because coda waves consist mainly of S-waves. We compare the 


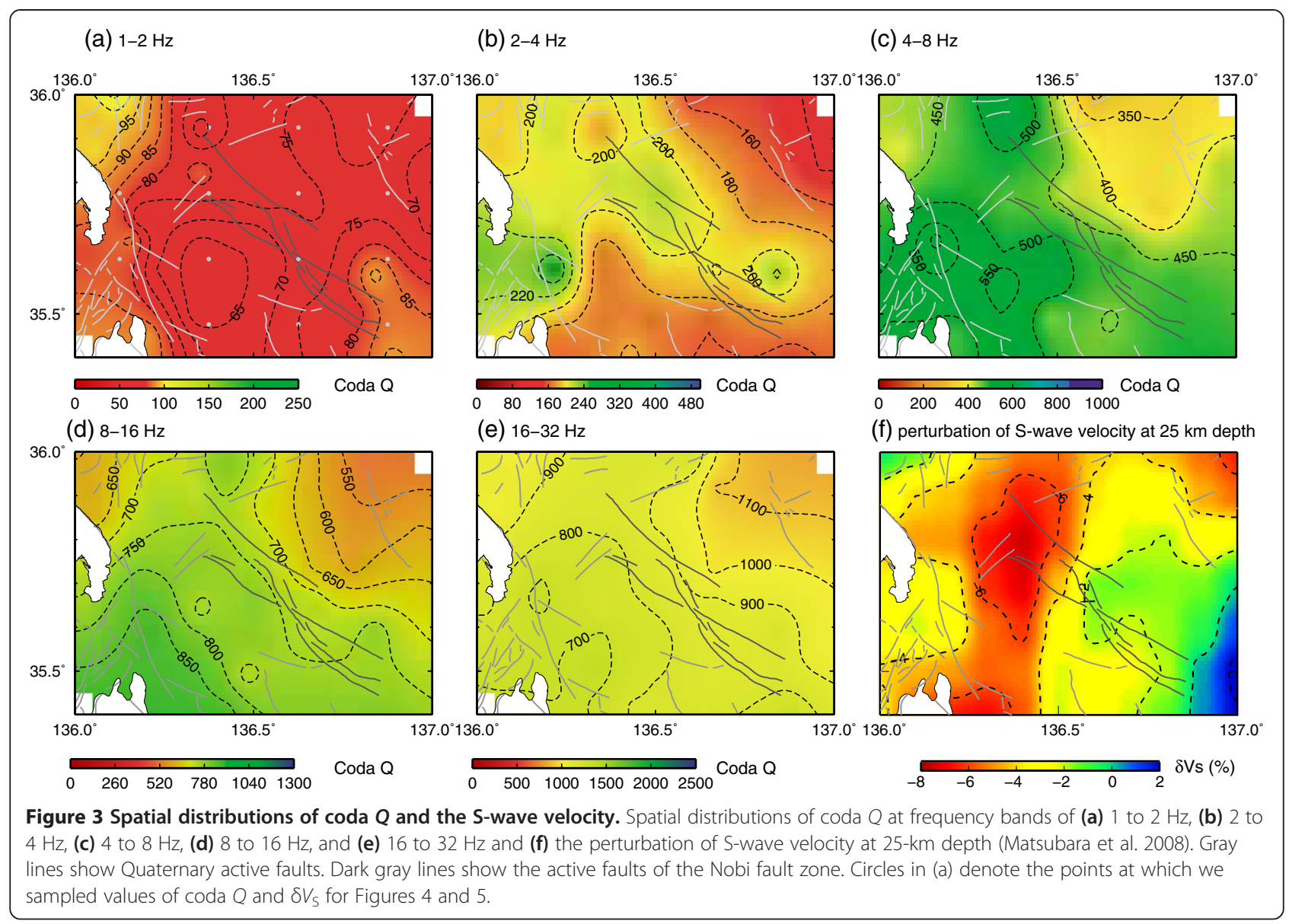

value of coda $Q$ at the frequency band of 1 to $2 \mathrm{~Hz}$ to the perturbations of $S$-wave velocity $\left(\delta V_{\mathrm{S}}\right)$ (Figure 3f) (Matsubara et al. 2008) at 0-, 15-, 25-, and 40-km depths (Figure 4). For comparison of these parameters, we resampled data at small areas that were separated by $15 \mathrm{~min} \times 7.5 \mathrm{~min}$ in the analyzed area (Figure 4). Coda $Q$ shows a positive correlation with $\delta V_{\mathrm{S}}$ at $25-\mathrm{km}$ depth, but it shows no clear correlation with $\delta V_{\mathrm{S}}$ at $0-$, 15-, and $40-\mathrm{km}$ depth. The correlation coefficients $R$ were -0.04 $(p=0.448)$ at $0-\mathrm{km}$ depth, $0.32(p=0.143)$ at $15-\mathrm{km}$ depth, $0.48(p=0.048)$ at $25-\mathrm{km}$ depth, and $-0.12(p=$ $0.348)$ at $40-\mathrm{km}$ depth. Here, the $p$ values represent the probability that we would have obtained for the current results if the correlation coefficients were actually zero. The value of $R$ at $25-\mathrm{km}$ depth was the only one that showed a significant correlation (if we apply a significance level of 95\%), although the correlation coefficient was not that high.

\section{Spatial correlation between coda $Q$ and seismicity}

Coda $Q$ is regarded as a good indicator of tectonic activity such as seismicity because tectonically active regions show low coda $Q$ values and stable regions show high coda $Q$ values on a large scale (e.g., Singh and
Herrmann 1983). On a small scale, the Atotsugawa fault zone, which shows much higher seismicity than the surrounding region in central Japan, is characterized by lower coda $Q$ values at the 1.5 - and $2.0-\mathrm{Hz}$ frequency bands than the surrounding region (Hiramatsu et al. 2013). The region analyzed in this study, around the Nobi fault zone, is not large, but seismicity in this region shows spatial variation (Figure 1). We therefore examined the correlation between the spatial variation in seismicity and that in coda $Q$. To do so, we used the hypocenter catalog provided by the Japan Meteorological Agency for the years 2000 to 2011.

For comparisons between seismicity and coda $Q$, we divided the analyzed region into subregions with $15 \mathrm{~min} \times$ $7.5 \mathrm{~min}$ areas. We removed the remarked clusters of earthquakes using the declustering algorithm reported by Reasenberg (1985). The declustering is controlled effectively by the parameter $R_{\text {fact }}$, which determines the radius in which a new earthquake belongs to a cluster. We attempted to set several values ranging from 3-20 to $R_{\text {fact }}$ and confirmed that the following results and discussion are independent of the value of $R_{\text {fact }}$. We therefore set $R_{\text {fact }}=10$ in this study. The seismicity varies with depth in this area. We examined the correlation between seismicity 


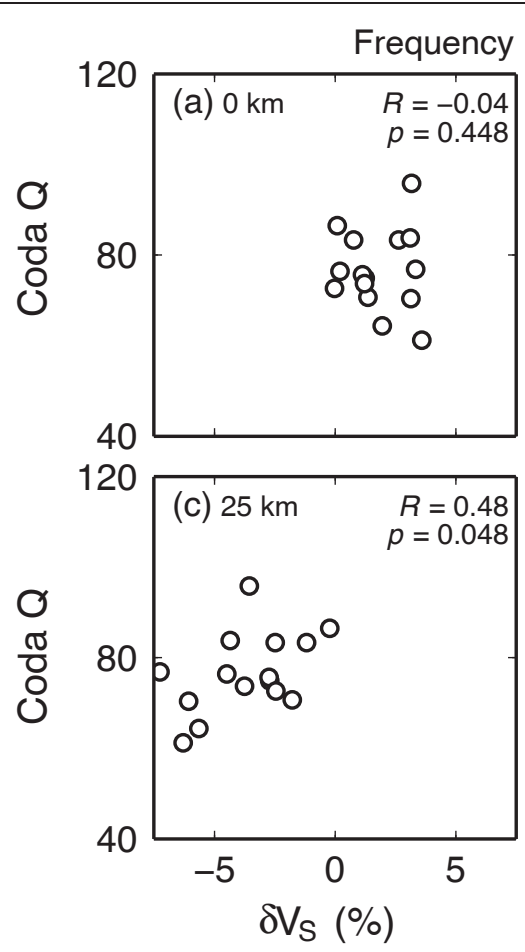

Band: $1-2 \mathrm{~Hz}$

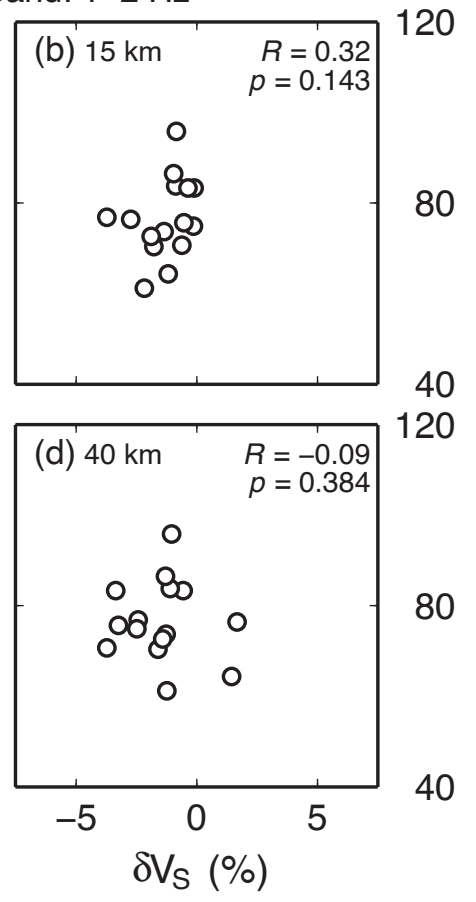

Figure 4 Relation between $\delta V_{S}$ and coda $Q$ at the 1- to 2-Hz frequency band. Plot of $\delta V_{S}$ (Matsubara et al. 2008) at (a) 0-, (b) 15-, (c) 25-, and (d) $40-\mathrm{km}$ depths versus coda $Q$ at the 1- to $2-\mathrm{Hz}$ frequency band. $R$ shows the correlation coefficient; $p$ is the $p$ value.

and coda $Q$ for two depth ranges: 5 to $10 \mathrm{~km}$ and 10 to $15 \mathrm{~km}$ (Figure 5a,b). In each of the subregions, we counted the declustered earthquakes greater than $M 2.0$ to confirm the uniform earthquake detection ability through the analyzed period over the analyzed area and to avoid the influence of slight perturbations in stress conditions; this was necessary because we specifically examined the background seismicity.

Figure 5c,d shows the correlation between coda $Q$ at the 1 - to $2-\mathrm{Hz}$ frequency band and the number of earthquakes at 5- to $10-\mathrm{km}$ depth and $10-$ to $15-\mathrm{km}$ depth, respectively. No significant correlation was found between coda $Q$ and the number of earthquakes at 5- to $10-\mathrm{km}$ depth, but a significant negative correlation was found between coda $Q$ and the number of earthquakes at 10to $15-\mathrm{km}$ depth. We also examined the correlation for higher frequency bands. The correlation at $5-$ to $10-\mathrm{km}$ depth was extremely weak: $|R|<0.1$. Furthermore, the correlation at 10 - to $15-\mathrm{km}$ depth was weak, $|R|<0.4$, for the higher frequency bands. We found a statistically significant correlation only between coda $Q$ at the 1 - to $2-\mathrm{Hz}$ frequency band and the number of earthquakes at 10 - to $15-\mathrm{km}$ depth.

\section{Discussion}

In the preceding sections, we demonstrated that coda $Q$ at the 1 - to $2-\mathrm{Hz}$ frequency band correlates positively with the shear wave velocity at $25-\mathrm{km}$ depth and negatively with the number of earthquakes at 10 - to $15-\mathrm{km}$ depth. Next, we discuss the causes of these correlations together with the results of previous works that were conducted to explore the high strain rate zone.

Around the Atotsugawa fault zone, Hiramatsu et al. (2013) found a low coda $Q$ zone at the $1.5-$ and $2-\mathrm{Hz}$ frequency bands, which corresponds to the low-velocity zone in the lower crust (Nakajima et al. 2010), and a positive correlation between coda $Q$ and $\delta V_{S}$. The observed positive correlation between coda $Q$ and $\delta V_{\mathrm{S}}$ in the lower crust in this study is coincident with this result. These facts confirm that the observed coda $Q$ at low frequencies reflects the seismic property primarily in the lower crust, which is below the brittle-ductile transition zone. Based on the creep model (Jin and Aki 1989) and the difference of the recovery process to a stepwise static stress change between coda $Q$ and seismicity in the Tamba region, southwest Japan (Sugaya et al. 2009), the variation in coda $Q$ is regarded as reflecting a variation in the ductile fracture below the brittle-ductile transition zone in the crust.

The strong frequency-dependent features of coda $Q$ imply that the variation in coda $Q$ is caused by the variation in the scattering property in the crust. Yomogida and Benites (1995) reported that the scattering is most effective at $\lambda \approx 2 a$, where $\lambda$ is the wavelength and $a$ is 


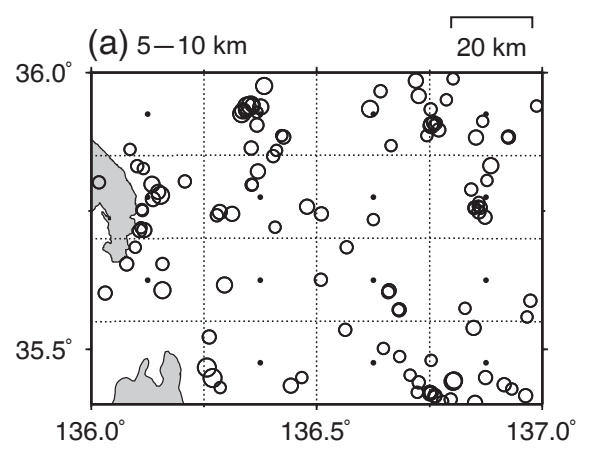

(b) $10-15 \mathrm{~km}$
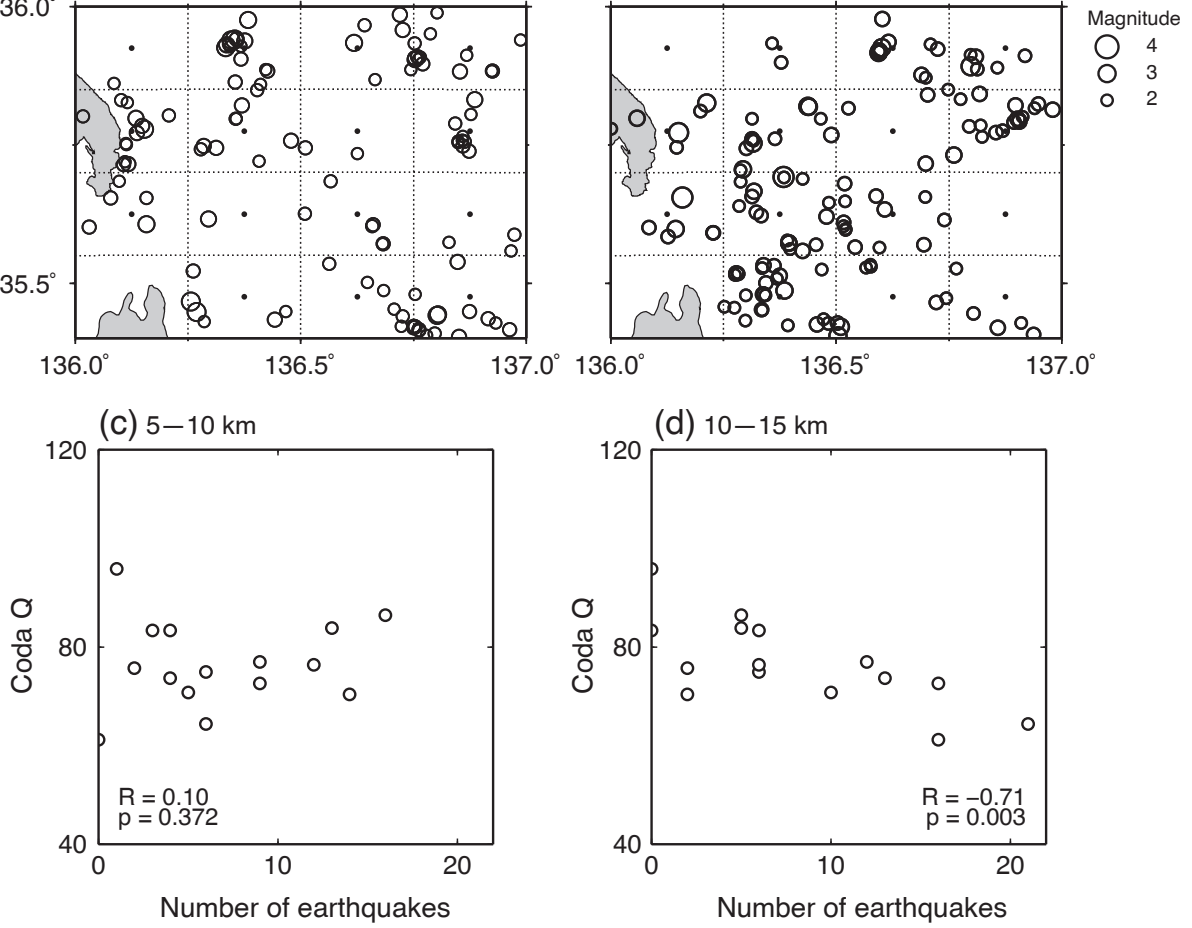

(d) $10-15 \mathrm{~km}$

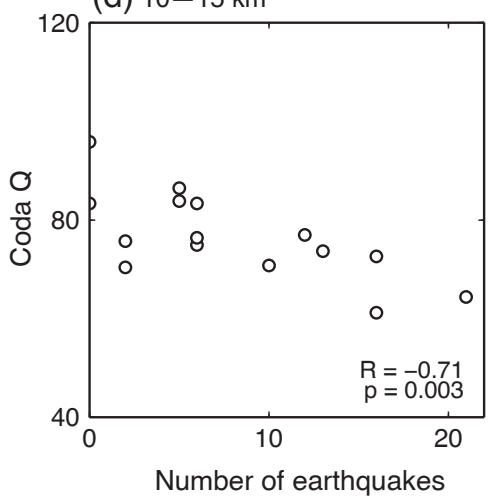

Figure 5 Relation between seismicity and coda Q. Distribution of earthquakes (circles) during 2000 to 2011, of which source depths are (a) 5 to $10 \mathrm{~km}$ and (b) 10 to $15 \mathrm{~km}$, and Quaternary active faults (gray lines). Rectangles bounded by dotted lines show the area in which we counted the earthquakes. Solid circles are points at which we sampled values of coda $Q$ shown in Figure 3. (c, d) The numbers of earthquakes versus the values of coda $Q$ at the 1 - to $2-\mathrm{Hz}$ frequency band. $R$ is the correlation coefficient; $p$ is the $p$ value.

the characteristic length of the scatterer from a numerical simulation. Therefore, the observed frequency-dependent correlations can be interpreted by the existence of a scatterer with a characteristic scale. As described above, the observed coda $Q$ at the 1 - to $2-\mathrm{Hz}$ frequency band reflects the seismic property at $25-\mathrm{km}$ depth. In other words, it is below the brittle-ductile transition zone in the crust. The average S-wave velocity at $25-\mathrm{km}$ depth in the analyzed region is about $3.7 \mathrm{~km} / \mathrm{s}$ (Matsubara et al. 2008), which gives a characteristic scale for the ductile fractures of about 1 to $2 \mathrm{~km}$. If the ductile fracture below the brittleductile transition zone in the crust has a characteristic scale of 1 to $2 \mathrm{~km}$, then the observed correlations can be explained.

As described in this paper, we present our findings of a negative correlation between coda $Q$ at the $1-$ to $2-\mathrm{Hz}$ frequency band and seismicity at $10-$ to $15-\mathrm{km}$ depth and a weak correlation between coda $Q$ at the 1 - to $2-\mathrm{Hz}$ frequency band and seismicity at $5-$ to $10-\mathrm{km}$ depth. From the results of spatial and temporal variations in shear wave splitting and coda Q, Hiramatsu et al. (2010, 2013) reported that coda $Q$ at lower frequencies is an indicator of the deformation rate below the brittle-ductile transition zone in the crust. Based on this idea, lower coda $Q$ values reflect a higher stressing rate. High deformation rates in the ductile lower crust provide high loading stress at the base of the brittle upper crust and cause high stressing rates in the brittle upper crust. A high stressing rate causes theoretically high seismicity based on laboratory experiences (Dieterich 1994). If the loading stress acts effectively at the deeper part of the brittle upper crust, then the observed negative correlation between coda $Q$ and the seismicity can be interpreted. For this reason, coda $Q$ at the 1 - to $2-\mathrm{Hz}$ frequency band correlates better with seismicity at 10 - to $15-\mathrm{km}$ depth than that at 5 to $10 \mathrm{~km}$.

The coda $Q$ estimated in this study is similar to those reported by Jin and Aki (2005) and Hiramatsu et al. (2013). However, slight variation in the differential strain rate in the analyzed area of 0.09 to $0.13 \mathrm{ppm} /$ year made it difficult to examine the correlation between coda $Q$ and the differential strain rate because the scatter of coda $Q$ is greater than the variation in the differential strain rate in this study.

\section{Conclusions}

Dense seismic observations around the Nobi fault zone in a high strain rate zone enabled us to determine the detailed spatial distribution of coda $Q$. Lower values of coda $Q$ at the 1 - to $2-\mathrm{Hz}$ frequency band are coincident with those in a previous study and confirm that this 
region can be characterized as a high strain rate zone. The spatial variation in coda $Q$ at the 1 - to $2-\mathrm{Hz}$ frequency band coincides with that for the low $\mathrm{S}$-wave velocity in the lower crust estimated by seismic tomography and with seismicity at $10-$ to $15-\mathrm{km}$ depth. These observations support the idea that coda $Q$ at lower frequencies is indicative of the deformation rate below the brittle-ductile transition zone in the crust.

\section{Competing interests}

The authors declare that they have no competing interests.

\section{Authors' contributions}

TS conducted the analyses. YH participated in the design of this study and drafted the manuscript. JUG participated in the design of this study and in the acquisition of data. All authors read and approved the final manuscript.

\section{Acknowledgements}

We thank the National Research Institute for Earth Science and Disaster Prevention and the Japan Meteorological Agency for allowing us to use the waveform data collected at each online station. All figures were produced using GMT software (Wessel and Smith 1998). Constructive comments from two anonymous reviewers helped to improve the manuscript. This research was partly supported by a grant offered under the Earthquake Prediction Research Program of the Ministry of Education, Culture, Sports, Science and Technology of Japan, and it was also supported by the cooperative research program of the Earthquake Research Institute, The University of Tokyo.

\section{Author details}

${ }^{1}$ Graduate School of Natural Science and Technology, Kanazawa University, Kakuma, Kanazawa 920-1192, Japan. 'Faculty of Natural System, Institute of Science and Engineering, Kanazawa University, Kakuma, Kanazawa 920-1192, Japan. ${ }^{3}$ Earthquake Research Institute, The University of Tokyo, Yayoi 1-1-1, Bunkyo, Tokyo 113-0032, Japan.

Received: 3 April 2014 Accepted: 12 August 2014

Published: 26 August 2014

\section{References}

Aki K, Chouet B (1975) Origin of coda waves: source, attenuation and scattering effects. J Geophys Res 80:3322-3342

Dieterich JH (1994) A constitutive law for rate of earthquake production and its application to earthquake clustering. J Geophys Res 99:2601-2618

Geospatial Information Authority of Japan (2011) The 2011 off the Pacific coast of Tohoku earthquake: crustal deformation and fault model (preliminary). http:// www.gsi.go.jp/cais/topic110422-index-e.html. Accessed 4 June 2014

Headquarters for Earthquake Research Promotion (2014) Long-term evaluation of active faults. http://www.jishin.go.jp/main/p_hyoka02_danso.htm. Accessed 4 June 2014

Hiramatsu Y, Hayashi N, Furumoto M, Katao H (2000) Temporal changes in coda $Q^{-1}$ and $b$-value due to the static stress change associated with the 1995 Hyogo-ken Nanbu earthquake. J Geophys Res 105:6141-6151

Hiramatsu Y, Honma H, Saiga A, Furumoto M, Ooida T (2005) Seismological evidence on characteristic time of crack healing in the shallow crust. Geophys Res Lett 32:L09304, doi: 10.1029/2005GL022657

Hiramatsu Y, Iwatsuki K, Ueyama S, lidaka T, the Japanese University Group of the Joint Seismic Observations at NKTZ (2010) Spatial variation in shear wave splitting of the upper crust in the zone of inland high strain rate, central Japan. Earth Planets Space 62:675-684

Hiramatsu Y, Sawada A, Yamauchi Y, Ueyama S, Nishigami K, Kurashimo E, the Japanese University Group of the Joint Seismic Observations at NKTZ (2013) Spatial variation in coda $Q$ and stressing rate around the Atotsugawa fault zone in a high strain rate zone, central Japan. Earth Planets Space 65:115-119

Jin A, Aki K (1989) Spatial and temporal correlation between coda $Q^{-1}$ and seismicity and its physical mechanism. J Geophys Res 94:14041-14059

Jin A, Aki K (2005) High-resolution maps of Coda Q in Japan and their interpretation by the brittle-ductile interaction hypothesis. Earth Planets Space 57:403-409
Matsubara M, Obara K, Kasahara K (2008) Three-dimensional P- and S-wave velocity structures beneath the Japan Islands obtained by high-density seismic stations by seismic tomography. Tectonophysics 454:86-103

Nakajima J, Hasegawa A (2007) Deep crustal structure along the Niigata-Kobe Tectonic Zone, Japan: its origin and segmentation. Earth Planets Space 59:e5-e8

Nakajima J, Kato A, Iwasaki T, Ohmi S, Okada T, Takeda T, The Japanese University Group of the Joint Seismic Observations at NKTZ (2010) Deep crustal structure around the Atotsugawa fault system, central Japan: a weak zone below the seismogenic zone and its role in earthquake generation. Earth Planets Space 62:555-566

Okada Y (1992) Internal deformation due to shear and tensile faults in a half-space. Bull Seismol Soc Am 82:1018-1040

Padhy S, Takemura S, Takemoto T, Maeda T, Furumura T (2013) Spatial and temporal variation in coda attenuation associated with the 2011 off the Pacific coast of Tohoku, Japan (Mw 9) earthquake. Bull Seismol Soc Am 103:1411-1428

Reasenberg PA (1985) Second-order moment of central California seismicity, 1969-1982. J Geophys Res 90:5479-5495

Research Group for Active Faults in Japan (1991) Active faults in Japan: sheet map and inventories (revised ed.). University of Tokyo Press, Tokyo (in Japanese)

Sagiya T, Miyazaki S, Tada T (2000) Continuous GPS array and present-day crustal deformation of Japan. PAGEOPH 157:2003-2322

Singh S, Herrmann RB (1983) Regionalization of crustal coda Q in the continental United States. J Geophys Res 88:527-538

Sugaya K, Hiramatsu Y, Furumoto M, Katao H (2009) Coseismic change and recovery of scattering environment in the crust after the 1995 Hyogo-ken Nanbu earthquake, Japan. Bull Seismol Soc Am 99:435-440

Wessel P, Smith WHF (1998) New, improved version of generic mapping tools released. Eos Trans Am Geophys Union 79:579

Yomogida K, Benites R (1995) Relation between direct wave Q and coda Q: a numerical approach. Geophys J Int 123:471-483

doi:10.1186/1880-5981-66-97

Cite this article as: Tsuji and Hiramatsu: Spatial variation in coda $Q$ around the Nobi fault zone, central Japan: relation to S-wave velocity and seismicity. Earth, Planets and Space 2014 66:97.

\section{Submit your manuscript to a SpringerOpen ${ }^{\circ}$ journal and benefit from:}

- Convenient online submission

- Rigorous peer review

- Immediate publication on acceptance

- Open access: articles freely available online

- High visibility within the field

- Retaining the copyright to your article

Submit your next manuscript at $>$ springeropen.com 